\title{
Artificial Neural Network Modeling for Sorption of Cadmium from Aqueous System by Shelled Moringa Oleifera Seed Powder as an Agricultural Waste
}

\author{
Abhishek Kardam ${ }^{1}$, Kumar Rohit Raj ${ }^{1}$, Jyoti Kumar Arora ${ }^{2}$, \\ Man Mohan Srivastava ${ }^{1}$, Shalini Srivastava ${ }^{1}$ \\ ${ }^{1}$ Department of Chemistry, Faculty of Science, Dayalbagh Educational Institute, Agra, India \\ ${ }^{2}$ Department of Mathematics, Technical College, Dayalbagh Educational Institute, Agra, India \\ E-mail:smohanm@rediffmail.com \\ Received December 26, 2009; revised January 15, 2010; accepted January 30, 2010
}

\begin{abstract}
A two-layer Artificial Neural Network (ANN) model was developed to predict the removal efficiency of Cd(II) ions from aqueous solution using shelled Moringa Oleifera seed (SMOS) powder. Batch experiments resulted into standardization of optimum conditions: biomass dosage $(4.0 \mathrm{~g}), \mathrm{Cd}(\mathrm{II})$ concentration $(25 \mathrm{mg} / \mathrm{L})$ volume $(200 \mathrm{~mL})$ at $\mathrm{pH} 6.5$. A time of forty minutes was found sufficient to achieve the equilibrium. The ANN model was designed to predict sorption efficiency of SMOS for target metal ion by combining back propagation (BP) with principle component analysis. A sigmoid axon was used as transfer function for input and output layer. The Levenberg-Marquardt algorithm (LMA) was applied, giving a minimum mean squared error (MSE) for training and cross validation at the ninth place of decimal.
\end{abstract}

Keywords: Artificial Neural Network, Biosorption, SMOS, Cd(II) Removal

\section{Introduction}

An increasing awareness about the environment motivated research has developed search for new efficient technologies that would be capable of treating heavy metal contaminated waste water in a cost effective manner. This search has brought newly emerging terms like Come back to nature, Grey to Green Chemistry and various Ecofriendly Green Technologies to the foreground of scientific interest as a potential basis for the design of novel waste water treatment processes. Conventional techniques used for the removal of heavy metals from waste water include filtration, precipitation, flocculation, ion exchange resins and reverse osmosis [1]. However, these methods are not economically viable if sophisticated instrumentation is utilized [2]. Various synthetic coagulants of aluminium (alum lime, aluminium sulphate, and poly aluminium silico sulphate), ferric salts (iron hydroxide and iron chloride) and soda ash were widely used as low cost processes. Research findings have clearly raised strong doubts against the use of synthetic coagulants [3].

In recent years, adsorption techniques have been widely investigated for the removal of heavy metals from waste water. Adsorbent used in the sorption processes are various materials including activated carbon obtained from agricultural by-products and commercial activated carbons [4]. However, the high cost of the activation process limits its use in wastewater treatment, particularly for the developing countries. Over the last few years, a number of investigations have been conducted to explore the low-cost adsorbents for the decontamination of toxic metals. Biosorption of heavy metals is one of the most promising and tangible alternatives to traditional methodologies. Sorption involves processes that reduce overall treatment cost through the application of agricultural wastes as they lessen reliance on expensive chemicals, negligible requirements of transportation and thus offering genuine, localized and appropriate solution to water treatment problems. Regeneration of the biosorbents adds another dimension to the cost effectiveness of the process thus warranting its future success.

To achieve an optimum management for any control measure, the concept of modeling for an efficient operation and design should be developed. A high quality representative model can provide a favorable solution to the process control. It is likely to explain the real process performance developing a continuous control strategy for 
such type of technologies. Because of reliable, robust and salient characteristics in capturing the non-linear relationships of variables in complex systems, applications of Artificial Neural Network (ANN) have been successfully employed in environmental engineering [5-7].

In continuation of our work on biosorption of toxic metals using shelled Moringa Oleifera seed (SMOS) powder from waste water [8-10], this paper describes a two-layer ANN model using a back propagation (BP) algorithm to predict the removal efficiency of SMOS for $\mathrm{Cd}(\mathrm{II})$ ions. Pursuing benchmark comparisons of BP algorithms, a study was conducted to determine the optimal network structure. The output obtained from the ANN modeling was compared with the experimental data. The present piece of work highlights the possibility of the prediction of sorption efficiency for the metal ions from waste water using SMOS in the range of metal concentration with which lab experiments have not been conducted.

\section{Materials and Methods}

\subsection{Biosorbent Preparation}

Moringa Oleifera Lam. tree was notified in the nearby area of Dayalbagh Educational Institute and the seeds were collected from the target plant. Seeds were washed thoroughly with double distilled water to remove the adhering dirt, dried at $65^{\circ} \mathrm{C}$ for $24 \mathrm{~h}$, crushed and sieved through (105) mesh copper sieves. Shelled Moringa Oleifera seeds (SMOS) were used as biosorbent.

\subsection{Biosorption Studies}

Sorption studies using standard practices were carried out in batch experiments (triplicate) as a function of biomass dosage (2.0-6.0 g), contact time (10-60 $\mathrm{min})$, volume of the test solution $(100-300 \mathrm{~mL}), \mathrm{Cd}$ concentration $(10-100 \mu \mathrm{g} / \mathrm{mL})$, particle size (105) and $\mathrm{pH}(4.5-8.5)$. The details of methodology have been described in our earlier publications [8-10]. Percent metal uptake by the sorbent was computed using the equation: \% Sorption = $\mathrm{Co}-\mathrm{Ce} / \mathrm{Co}$ 100, where $\mathrm{Co}$ and $\mathrm{Ce}$ were the initial and final concentration of metal ions in the solution.

\subsection{Definition of the ANN Model}

Neural Network Toolbox Neuro Solution 5 ( mathematical software was used to predict the sorption efficiency. One hundred eighty experimental sets were used to develop the ANN model. A two layer ANN with sigmoid axon transfer function was used for input and output layers. The data gathered from batch experiments were divided into input matrix and desired matrix. The two layer sigmoid network represents functional rela- tionship between inputs and output, provided sigmoid layer has enough neurons. Levenberg-Marquardt algorithm is fastest training algorithm for network of moderate size, therefore, used in the present study.

\section{Results and Discussions}

\subsection{Sorption Studies}

Sorption studies led to the standardization of the optimum conditions as: metal concentration $(25 \mathrm{mg} / \mathrm{L})$, biomass dosage $(4.0 \mathrm{gm})$, contact time (40 $\mathrm{min})$ and volume $(200 \mathrm{~mL})$ at $\mathrm{pH} 6.5$ for maximum $\mathrm{Cd}$ removal $(85.10 \%)$. The effect of various experimental parameters was studied and compared with performance of ANN model.

\subsection{Selection and Optimization of the ANN Structure}

The removal of Cd(II) ion using SMOS was calculated in the laboratory batch experiments as a function of biomass dosage, contact time, volume of the solution and metal ion concentration in terms of percentage sorption. ANN model based on two layered recurrent back propagation algorithm for the experimental data, generated from the above batch experiments was applied to train the neural network. During training, the output vector is computed by a forward pass in which the input is propagated forward through the network to compute the output value of each unit. The output vector is then compared with the desired vector which resulted into error signal for each output unit. In order to minimize the error, appropriate adjustments were made for each of the weights of the network. After several such iterations, the network was trained to give the desired output for a given input vector. The two layer network structure included fifteen hidden neurons for layer one and twelve hidden neurons for layer two, describing the dynamics of $\mathrm{Cd}(\mathrm{II})$ in effluent (Figure 1). The sigmoid axon was considered

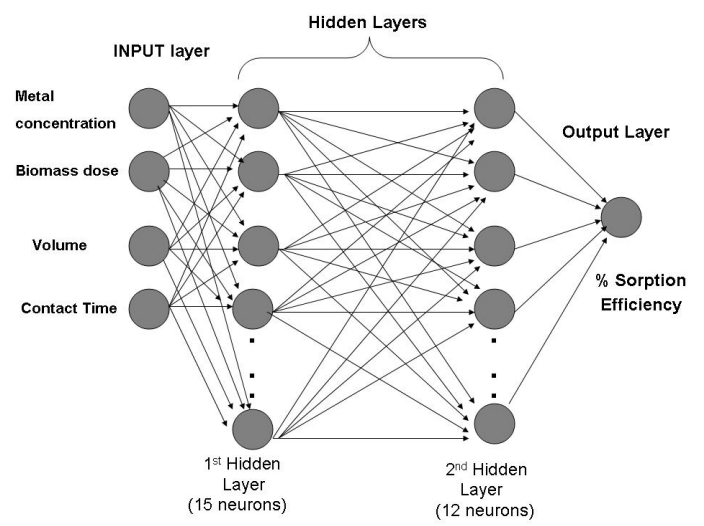

Figure 1. Two layer Optimum Neural Network structure for the prediction of the biosorption efficiency. 
transfer function with 0.7 momentums. The performance of network simulation was evaluated in terms of mean square error (MSE) criterion. The MSE for the training and cross validation data sets were found at the ninth place of decimal. The developed network model was examined for its ability to predict the response of experimental data not forming the part of the training program. Figure 2 shows the result obtained by the neural network simulation for both the training and cross validation data sets. The $\mathrm{Cd}(\mathrm{II})$ ion concentrations were precisely predicted for the training data sets.

\subsection{Sensitivity Analysis}

A sensitivity analysis was conducted to determine the degree of effectiveness of variables. Performance of the groups of input vectors included biomass dosage, Cd(II) ion concentration, contact time and volume. Series of experiment resulted into the evaluation of performance based on $10 \%$ data for testing and $20 \%$ data for cross validation at 32000 Epoch with 0.70000 momentums. The minimum MSE in the group of four variables was
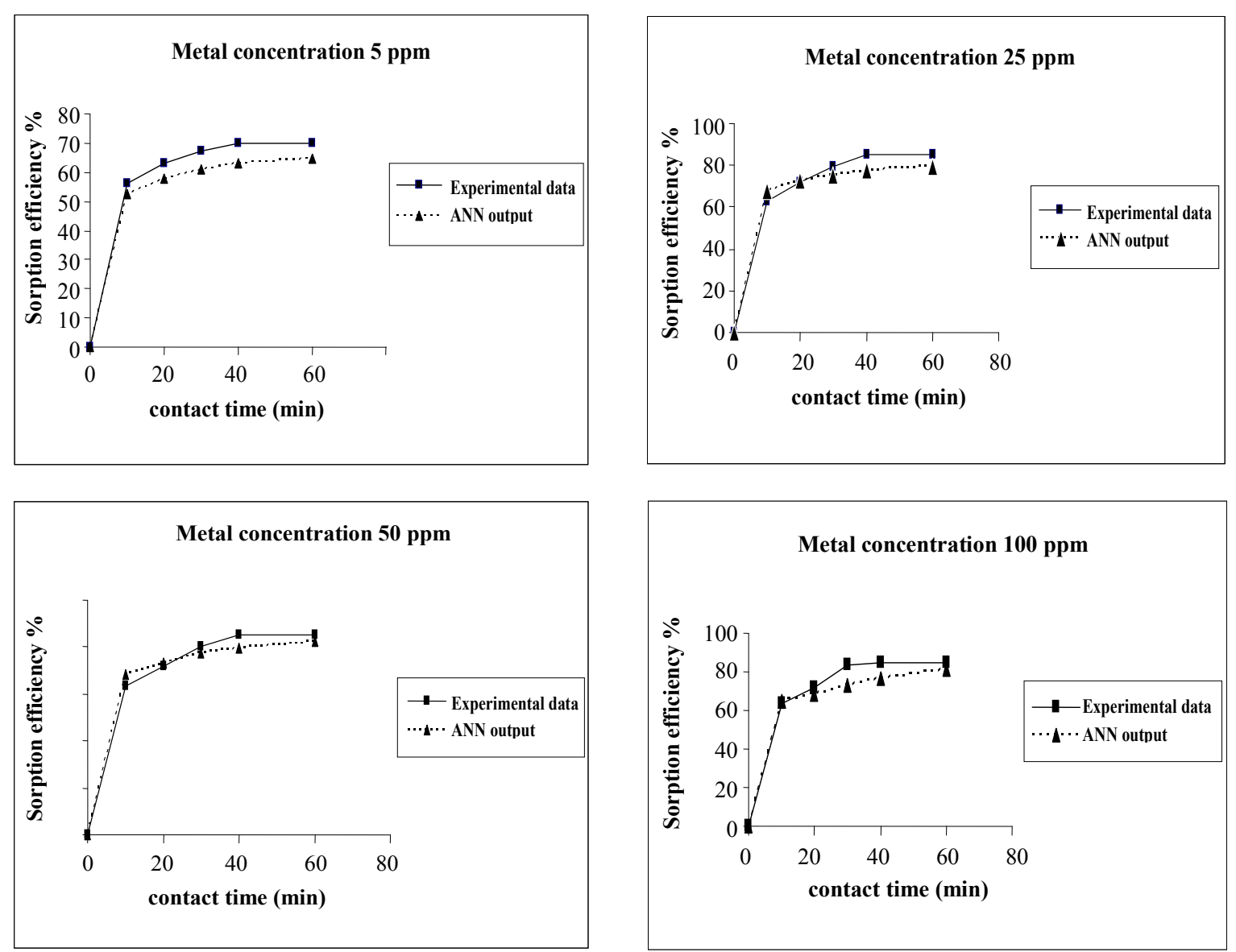

Figure 3. Agreement between ANN outputs and experimental data as a function of metal concentration (biomass dosage $=4.0$ $\mathrm{g}$, volume $=200 \mathrm{~mL}$ and $\mathrm{pH}=6.5$ ). 
the sorption behavior of $\mathrm{Cd}$ on SMOS in the range of metal concentration (10-100 mg/L). Sorption of $\mathrm{Cd}$ on SMOS increased with increasing concentration of the metal ion reaching to an optimal level $(25 \mathrm{mg} / \mathrm{L})$. Later, an increase in concentration decreased the percentage binding. These observations can be explained by the fact that at medium concentrations, the ratio of sorptive surface area to metal ions available is high and thus, there is a greater chance for metal removal. When metal ion concentrations are increased, binding sites become more quickly saturated as the amount of biomass concentration remained constant [11]. The comparison of experimental data and ANN outputs for Cd(II) ions concentrations shows that the ANN model performed well for prediction of the experimental data.

\subsection{Effect of Biomass Dosage on the Sorption Efficiency}

Percent sorption increased with the increase of biomass dosage from 2.0 to $4.0 \mathrm{~g}$. However, no significant increment in the sorption tendency was observed on further increasing the biomass dosage from $4.0 \mathrm{~g}$ onwards. This might be due to attainment of equilibrium between adsorbate and adsorbent at the existing operating conditions rendering adsorbent incapable of further adsorption. The amount of biomass (4.0 g) used in present case seems to be quite reasonable, as practically similar sorption efficiencies for the same set of metals were reported with relatively higher biomass dosages from 6.0 to $10.0 \mathrm{~g}$ of different biosorbents like Okra wastes [12] and Nile rosa [13]. A perusal of experimental data and ANN outputs as a function of biomass dosages (Figure 4) depicted performance of the model in good harmony with the experimental data.

\subsection{Effect of Initial Volume on the Sorption Efficiency}

The effect of volume on the percent sorption of $\mathrm{Cd}(\mathrm{II})$ on SMOS was observed under similar experimental conditions in different set of volumes (100-300 mL). Maximum sorption was obtained in the volume $(200 \mathrm{~mL})$ of the test solution. It shows that the ratio of sorption surface of the SMOS to total Cd ions availability is optimum, exhibiting maximum percentage removal (85.10\%). ANN model showed performance in resemblance with experimental data (Figure 5).

\subsection{Effect of Contact Time on the Sorption Efficiency}

The effect of contact time on Cd(II) sorption on SMOS was studied for duration of 10-60 minutes. The percent sorption of metal ion gradually increased with time from
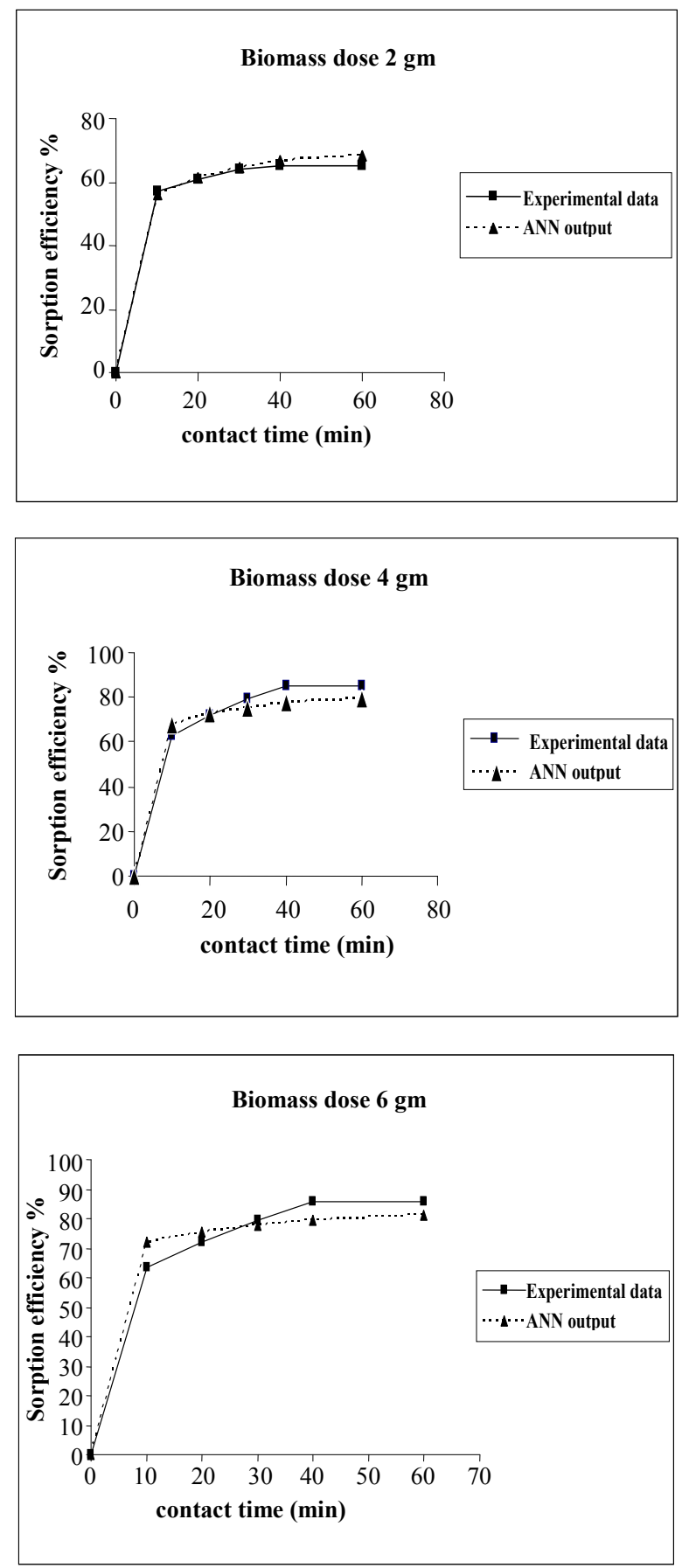

Figure 4. Agreement between ANN outputs and experimental data as a function of biomass dosage (metal concentration $=25 \mathrm{mg} / \mathrm{L}$, volume $=200 \mathrm{~mL}$ and $\mathrm{pH}=6.5$ ).

10 to 30 minutes, finally reaching the optimum value at 40 minutes. Once equilibrium was attained, the percentage sorption of $\mathrm{Cd}(\mathrm{II})$ ion did not change with further increase of time. On comparison basis, sorption efficiency of the present process is much better than earlier reported contact time ranging from 60 to 120 minutes for same metals shown by other agricultural byproducts such 

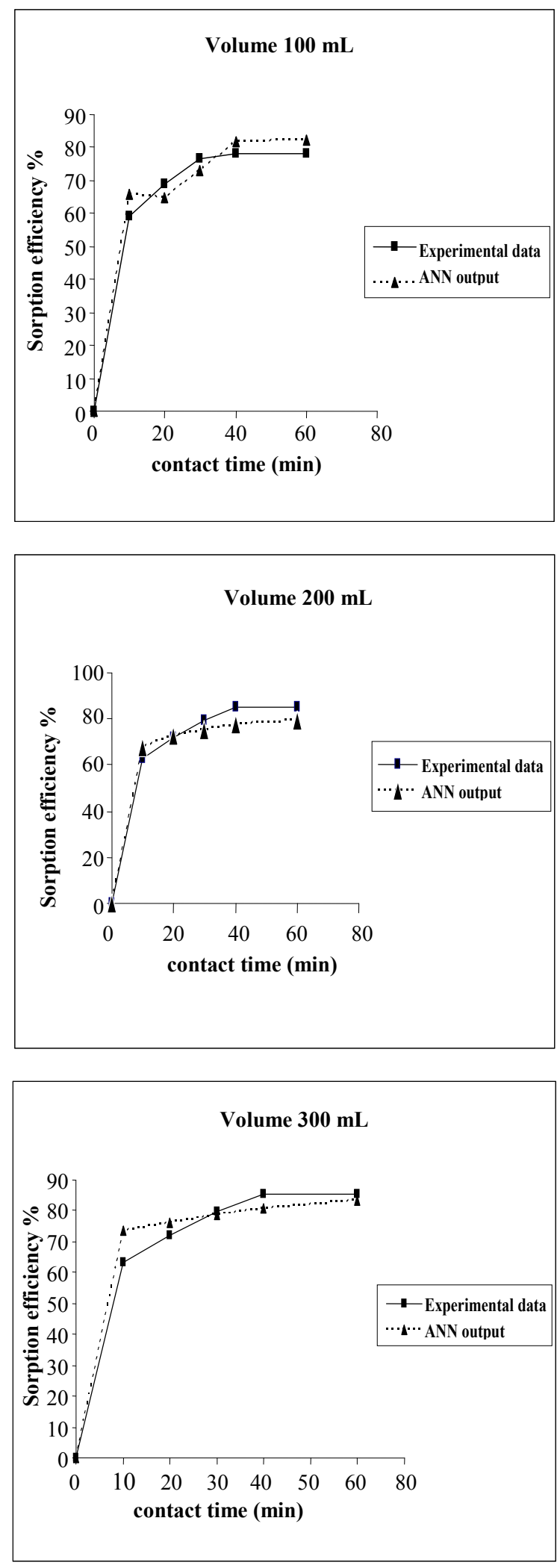

Figure 5. Agreement between ANN outputs and experimental data as a function of volume (metal concentration = $25 \mathrm{mg} / \mathrm{L}$, biomass dose $=4.0 \mathrm{~g}$ and $\mathrm{pH}=6.5$ ). as corn cob [14] and Rice husk [15]. ANN model prediction was found in match with experimental data.

\subsection{Effect of pH on Sorption Efficiency}

The $\mathrm{pH}$ of a suspension is an important factor that can affect the percentage sorption of $\mathrm{Cd}(\mathrm{II})$ ion on SMOS. The sorption efficiency increases, as the $\mathrm{pH}$ of the solution is increased from 4.5 to 8.5 . The $\mathrm{pH}$ profile for $\mathrm{Cd}(\mathrm{II})$ sorption on seed powder shows that metal sorption is a function of $\mathrm{pH}$, exhibiting maximum sorption at $\mathrm{pH} 6.5$. There was no significant difference in sorption behavior with further increase in $\mathrm{pH}$ up to 7.5. Investigation on $\mathrm{pH}$ variation beyond 7.5 yielded an increase in sorption up to $\mathrm{pH} 8.5$ which might be due to the precipitation carryover of $\mathrm{Cd}(\mathrm{II})$ ion which starts at $\mathrm{pH} 7.5$ [16]. As the $\mathrm{pH}$ of the solution increases from 4.5 to $7.5, \mathrm{Cd}(\mathrm{II})$ ion reflects increased binding behavior to the biomass with optimum binding at $\mathrm{pH}$ 6.5. SMOS seed powder prominently contains low molecular weight amino acid. Amino acids have been found to constitute a physiologically active group of transporters, working even at low concentration, which because of ability to interact with metal ions is likely to increase their mobility [17]. These Proteinaceous amino acids have variety of structurally related $\mathrm{pH}$ dependent properties of generating appropriate atmosphere (positively and/or negatively charged sites) for attracting the cationic and anionic species of metal ions [18]. Therefore, ANN model predictions were made at optimum $\mathrm{pH} 6.5$.

\section{Conclusions}

The present work demonstrates the $85.10 \%$ removal of $\mathrm{Cd}(\mathrm{II})$ ions from the aqueous solutions using Moringa Oleifera seeds at optimized parameters of the process. The two layer ANN modeling technique is allowed to optimize this process. The Levenberg-Marquardt algorithm (LMA) was found best of BP algorithms with a minimum mean squared error (MSE) for training and cross validation as 0.000923838 and 0.003707393 respectively. Thus a simple back propagation of the recurrent network using the momentum training algorithm is proved meaningful supplement for the conventional and complicated mathematical models in the prediction of bioprocess.

\section{Acknowledgements}

The authors gratefully acknowledge Prof. V.G. Das, Director and Prof. L.D. Khemani, Head, Department of Chemistry, Dayalbagh Educational Institute, Dayalbagh, Agra. Dr. Sandeep Paul, Technical College, Dayalbagh Educational Institute is also acknowledged for fruitful scientific discussions. 


\section{References}

[1] K. H. Rostami and M. R. Joodaki, "Some Studies of Cadmium Adsorption Using Aspergillus Niger, Penicillium Austurianum, Employing an Airlift Fermenter," Chemical Engineering Journal, Vol. 89, No. 1-3, October 2002, pp. 239-252.

[2] A. Basu, S. Kumar and S. Mukherjee, "Arsenic Reduction from Environment by Water Lettuce (Pistia stratiotes L.)," Indian Journal of Environmental Health, Vol. 45, No. 2, April 2003, pp. 143-150.

[3] T. Okuda, A. U. Baes, W. Nishijima and M. Okada, "Isolation and Characterization of Coagulant Extracted from Moringa Oleifera Seed by Salt Solution," Water Research, Vol. 35, No. 2, February 2001, pp 405-410.

[4] S. J. Park and Y. S. Jang, "Pore Structure and Surface Properties of Chemically Modified Activated Carbons for Adsorption Mechanism and Rate of Cr (VI)," Journal of Colloid and Interface Science, Vol. 249, No. 2, May 2002, pp 458-463.

[5] Y.-S. Park, T.-S. Chon, I.-S. Kwak and S. Lek, "Hierarchical Community Classification and Assessment of Aquatic Ecosystems Using Artificial Neural Networks," Science of the Total Environment, Vol. 327, No. 1-3, July 2004, pp. 105-122.

[6] L. Belanche, J. J. Valdes, J. Comas, I. R. Roda and M. Poch, "Prediction of the Bulking Phenomenon in Wastewater Treatment Plants," Artificial Intelligence in Engineering, Vol. 14, No. 4, October 2000, pp. 307-317.

[7] G. R. Shetty and S. Chellam, "Predicting Membrane Fouling during Municipal Drinking Water Nanofiltration Using Artificial Neural Networks," Journal of Membrane Science, Vol. 217, No. 1-2, June 2003, pp 69-86.

[8] P. Sharma, P. Kumari, M. M. Srivastava and S. Srivastava, "Removal of Cd from Aqueous System by Shelled Moringa Oleifera Lamarck Seed Powder," Bioresourse Technology, Vol. 97, No. 2, 2006, pp.299-305.

[9] P. Sharma, P. Kumari, M. M. Srivastava and S. Srivastava, "Ternary Biosorption Studies of Cd(II), Cr(III) and Ni(II) on Shelled Moringa Oleifera Seeds," Bioresourse Technology, Vol. 98, No. 2, January 2007, pp. 474- 477.
[10] P. Sharma, P. Kumari, M. M. Srivastava and S. Srivastava, "Biosorption Studies on Shelled Moringa Oleifera Lamarck Seed Powder: Removal and Recovery of Arsenic from Aqueous System," International Journal of Mineral Processing, Vol. 78, No. 3, February 2006, pp. 131-139.

[11] K. Yetilmezsoy and S. Demirel, "Artificial Neural Network (ANN) Approach for Modeling of Pb (II) Adsorption from Aqueous Solution by Antep Pistachio (Pistacia Vera L.) Shells," Journal of Hazardous Materials, Vol. 153, No. 3, May 2008, pp. 1288-1300.

[12] M. A. Hashem, "Adsorption of Lead Ions from Aqueous Solution by Okra Wastes," International Journal of Physical Science, Vol. 2, No. 7, 2007, pp. 178-184.

[13] N. T. Abdel-Ghani and G. A. Elchaghaby, "Influence of Operating Conditions on the Removal of $\mathrm{Cu}, \mathrm{Zn}, \mathrm{Cd}$ and $\mathrm{Pb}$ Ions from Wastewater by Adsorption," International Journal of Environmental Science and Technology, Vol. 4, No. 4, 2007, pp. 451-456.

[14] H. Parmar, J. Patel, P. Sudhakar and V. J Koshi, "Removal of Fluoride from Water with Powdered Corn cobs," Journal of Environmental Science and Engineering, Vol. 48, No. 2, 2006, pp. 135-138.

[15] N. T. Abdel-Ghani, M. Hefny and G. A. F. El-Chaghaby, "Removal of Lead from Aqueous Solution Using Low Cost Abundantly Available Adsorbents," International Journal of Environmental Science and Technology, Vol. 4, No. 1, 2007, pp. 67-73.

[16] M. Iqbal, A. Saeed and N. Akhtar, "Petiolar Felt-Shealth of Palm: A New Biosorbent for the Removal of Heavy Metals from Contaminated Water," Bioresourse Technology, Vol. 81, No. 2, January 2002, pp. 151-153.

[17] A. C. Brostlap and J. Schuurmans, "Kinetics of L-valine Uptake in Tobacco Leaf Disc. Comparison of Wild-Type, the Digenic Mutant $\mathrm{Val}^{\mathrm{r}}-2$, and its Monogenic Derivatives," Planta, Vol. 176, No. 1, November 1988, pp. 4250.

[18] G. Costa, J. C. Michant and A. Guckert, "Amino Acids Exuded from Axenic Roots of Lettuce and White Lupin Seedlings Exposed to Different Cadmium Concentrations," Journal of Plant Nutrition, Vol. 20, No. 7-8, 1997, pp. 883-900. 